\title{
Identidade e saberes docentes constituídos durante a formação inicial de professores de física: um estudo de caso
}

Beatriz Salemme Corrêa Cortela biacortela@fc.unesp.br 0000-0002-1821-3106 Universidade Estadual Paulista "Júlio de Mesquita Filho", São Paulo, São Paulo, Brasil.

Sandra Regina Teodoro Gatti sandragatti@fc.unesp.br 0000-0001-5791-2498 Universidade Estadual Paulista "Júlio de Mesquita Filho", São Paulo, São Paulo, Brasil.

Roberto Nardi nardi@fc.unesp.br 0000-0002-5018-3621 Universidade Estadual Paulista "Júlio de Mesquita Filho", São Paulo, São Paulo, Brasil.

\begin{abstract}
RESUMO
Trata-se de um excerto de uma investigação que buscou estudar o processo de constituição da identidade docente em diferentes tempos formativos a partir da aquisição de saberes. Visou analisar as múltiplas relações que envolvem a aquisição e a mobilização dos mesmos em diferentes etapas, desde a formação inicial até o exercício da profissão. Relata-se, aqui, um estudo realizado com os alunos de um curso de licenciatura em Física, nas disciplinas de Metodologias e Práticas de Ensino, numa perspectiva longitudinal. O instrumento para constituição de dados foi um questionário semiestruturado. São apresentadas sínteses das respostas referentes aos saberes atribuídos aos bons professores e sobre a satisfação com a profissão escolhida. Concluiu-se que, ao longo do curso, os alunos ampliaram e aprofundaram seus saberes, favorecidos, entre outros aspectos, pela forma como a estrutura curricular do curso foi organizada; pelo modo que os docentes das disciplinas didático-pedagógicas trabalham; e pelo perfil desses formadores.
\end{abstract}

PALAVRAS-CHAVE: Identidade docente. Saberes docentes. Profissionalidade docente. 


\section{INTRODUÇÃO}

Este artigo apresenta alguns resultados de um processo investigativo maior e que visa compor um panorama sobre o processo de constituição da identidade docente em diferentes tempos e espaços formativos, a partir da aquisição de saberes. Entre as diversas abordagens possíveis para as pesquisas sobre formação de professores e saberes docentes existe aquela chamada por Borges (2004) de profissional, que está inserida na ideia de que os professores são produtores de saberes e que existe um saber que emerge de sua prática profissional. Estão dentro desta categoria os trabalhos de Gauthier et al. (1998); Schön et al. (2000); Tardif, Lessard et al. (2005); Zeichner, Pereira et al. (2005), entre outros.

$\mathrm{Na}$ concepção dos autores supracitados, os saberes docentes são considerados como sendo sociais, plurais e, de certa forma, contínuos uma vez que são incorporados pelos sujeitos ao longo da vida. Sociais à medida que são obtidos e modificados ao longo da carreira docente, ou seja, é um saber decorrente de um processo contínuo de aprendizagem, desde a formação inicial até o exercício profissional, na busca pelo domínio do seu ambiente de trabalho. Mesmo sendo condicionados pelo trabalho "[...] estão longe de serem produzidos por eles mesmos ou se originarem de seu trabalho cotidiano" (TARDIF, 2007, p.19). Neste sentido, são também plurais: alguns provêm da família, outros da escola que o formou; de sua cultura pessoal; outros estão ligados à instituição de ensino onde trabalha, aos cursos de formação em serviço e/ou continuada dos quais participa, e assim por diante. Assim, os saberes docentes não estão separados dos seus condicionantes ou do contexto onde se inserem. Ou seja, "[...] o saber é sempre o saber de alguém que trabalha alguma coisa no intuito de realizar um objetivo qualquer" (TARDIF, 2007, p.11).

Além disso, é um saber que não está desligado do sujeito que o detém, de sua identidade, de sua experiência de vida, de sua história profissional, de suas expectativas em relação aos seus alunos e às turmas com as quais trabalha. Pois, ao mesmo tempo em que ministra aulas para grupos de alunos, o professor deve buscar zelar pela aprendizagem de cada um deles, ou seja, atingir o indivíduo. Deste modo, necessita estar apto a compreender também as características individuais e situacionais de seus alunos, considerando aspectos psicológicos das diferentes faixas etárias e seus condicionantes sociais.

Em se tratando da identidade profissional, há fatores subjetivos que envolvem questões relativas àquilo que é particular ao sujeito, tais como personalidade, gostos, aptidões, valores, entre outros. Há, também, fatores objetivos que remetem a questões de ordem social, cultural e econômica, tanto dos sujeitos quanto da época e sociedade em que vivem. Assim, identidade é um conceito altamente complexo por contemplar e ser estudado por vários campos do conhecimento, como a Psicologia e a Sociologia.

Adota-se, aqui, a concepção de identidade proposta por Dubar (2005), sociólogo francês, que defende que a identidade é fruto de processos de socialização, os quais são compostos por combinações de processos relacionais e biográficos, numa perspectiva de uma identidade para o outro, que tem um caráter mais genérico e objetivo, e a identidade para si, mais específico e subjetivo.

No que diz respeito à identidade para o outro, na concepção do autor supracitado, trata-se de um processo decorrente de atos de atribuição, que são 
formas de representação que criam uma identidade social, dita virtual, de uma determinada classe. $O$ que determina esses atos é o sistema de ação em que o indivíduo está envolvido, ou seja, as condições contextuais vivenciadas. Em decorrência disso, para analisar a constituição de uma identidade profissional dos licenciandos, participantes da investigação, fez-se necessário conhecer o contexto de produção das relações vivenciadas, ou seja, a estrutura do curso e o perfil profissional pretendido, presente no Projeto Pedagógico do Curso (PPC), além do perfil profissional de seus docentes formadores. Reflexões decorrentes destes fatores são apresentadas no item 'metodologia da pesquisa e descrição do campo'.

Isso significa que a identidade para o outro é também a forma pela qual determinado grupo identitário é representado socialmente, sendo que esta é constituída tanto pelos sujeitos ativos, considerados por Dubar (2005) como sendo aqueles integrantes de um determinado grupo ou classe em discussão, quanto por aqueles não pertencentes aos mesmos. Por exemplo, quando se discute sobre a identidade profissional docente existem as representações mediadas tanto por aqueles que são professores (sujeitos ativos) quanto por aqueles que não são, ou seja, os pertencentes às mídias, gestores públicos, alunos, pais, entre outros.

Quanto aos processos biográficos, que caracterizam a identidade para si, estes provêm da incorporação da identidade no sujeito ativo mediante suas trajetórias sociais e profissionais. Assim, fez-se necessário conhecer o perfil social dos licenciandos e o fluxo formativo do curso de licenciatura em questão que, de certa forma, dão indícios de como os estudantes lidam com as dificuldades inerentes de seu trajeto formativo e efetuam suas escolhas profissionais. Reflexões decorrentes destes fatores são apresentadas no item 'metodologia da pesquisa e descrição do campo'.

Considera-se que a profissionalidade, expressão que significa um amálgama de profissionalização e identidade, com sendo um conjunto de capacidades e saberes desenvolvidos pelos docentes no desempenho das suas funções, em diferentes momentos do processo de sua profissionalização (BRZEZINSKI, 2002; LIBÂNEO, 2000). Ou seja, um processo de constituição e identificação profissional, desenvolvido pelos professores ao longo da vida, em diferentes espaços de socialização, desde o início de sua formação até a atuação profissional.

A profissionalidade se refere ao que há de específico em cada profissão. Sua principal característica é a instabilidade, uma vez que, como dito anteriormente, essa se constrói progressivamente em determinados contextos, portanto, dentro de diferentes momentos históricos e influenciada por diversos sujeitos. Neste sentido, não pode ser analisada somente a partir de um conjunto de características definidas a priori, mas deve ser entendida como uma construção social. Concordando com Zeichner (1990, apud MARCELO GARCÍA, 1999, p.250), “[...] o processo de socialização docente é ao mesmo tempo contraditório e dialético, coletivo e individual e situado num contexto mais amplo de instituições, sociedade, cultura e história".

Essa noção de construção social significa que as profissões não são realidades naturais, mas sócio-históricas, por um lado; e, por outro, que essas realidades não são produzidas por qualquer determinismo "[...] mas, sim pela acção dos atores sociais que agem em contextos já condicionados, mas que oferecem aos actores algumas possibilidades, algumas margens de manobra, espaços de jogo, etc." (TARDIF; LESSARD, 2005, p. 11). 
Vários autores (BORGES, 2004; PIMENTA, 2002; TARDIF, 2007) identificaram uma série de saberes que influenciam a prática docente, apontando que muitos deles são adquiridos anteriormente a esta, ou seja, desenvolvidos durante o processo formativo, inicial e/ou continuado. Apesar das diferentes nomenclaturas, que por vezes remetem aos mesmos sentidos, consideram-se aqui aqueles definidos por Tardif:

\footnotetext{
i. os saberes da formação profissional, ou seja, das ciências da educação e da ideologia pedagógica;

ii. os disciplinares, correspondentes aos vários campos do conhecimento e que estão integrados na forma de disciplinas;

iii. os curriculares, que se apresentam na forma de programas escolares, selecionados como modelos da cultura erudita;

iv. os experienciais ou práticos (e não da prática, mas que se integram a ela e dela são partes constituintes) e que compõem uma série de representações a partir das quais estes profissionais compreendem e tomam decisões em sua prática cotidiana, ou seja, os saberes experienciais constituem o que o autor supracitado chama de 'cultura docente em ação' (TARDIF, 2007, p.49).
}

São estes saberes experienciais, explicitados por licenciandos em Física que estavam cursando o penúltimo ano do curso, em 2017, que foram foco das análises aqui apresentadas. Este artigo visa apresentar e discutir resultados de um levantamento de dados coletados em dois momentos diferentes (2015 e 2017) e tendo como participantes os mesmos alunos, ao final de duas disciplinas, Metodologia e Prática de Ensino de Física II e V (MPEF II e MPEF V), oferecidas no segundo e quinto semestres, respectivamente, de um curso de formação inicial de professores de Física de uma universidade pública.

A estruturação e implementação destas disciplinas, desde 2013, visa à superação de alguns dos desafios atuais da docência universitária, que são também os dos autores. Entre estes, buscar romper com a forma tradicional de ensinar; reconfigurar saberes, visando superar dicotomias referentes à teoria e a prática; e explorar novas alternativas teórico-metodológicas (VEIGA, 2009), utilizando abordagens de ensino ativas, adotando a pluralidade metodológica, desenvolvendo atividades que favoreçam a metacognição, dentro de uma perspectiva crítica.

Considera-se, também, que refletir sobre a própria prática a partir de um olhar teorizado e escrever sobre ela seja um dos caminhos visando a validação dos saberes experienciais com vista à construção de saberes da ação pedagógica, assim caracterizados por Gauthier et al. (1998). Neste sentido, os autores se propõem a este desafio, explicitando o contexto de produção de suas pesquisas e apresentando dados decorrentes de parte de suas investigações e de suas constituições enquanto docentes de uma universidade pública brasileira, atuando como formadores de professores de Física que ministrarão aulas, primordialmente, na educação básica.

Tendo em perspectiva que existem muitas questões a serem discutidas e adotando a ideia de desafio enquanto algo a ser superado em situação para a qual ainda não se construiu conhecimento suficiente, objetiva-se, também, refletir sobre os desafios enfrentados por docentes que atuam como formadores de professores ao planejarem e desenvolverem práticas pedagógicas levando em consideração o conceito de simetria invertida (BRASIL, 2002). Ou seja, buscando manter coerência entre as ações empreendidas durante a formação de um 
professor e o que dele se espera enquanto profissional, sem desconsiderar o isomorfismo.

Cada nível educativo tem possibilidades e necessidades didácticas diferentes. No entanto, na formação de professores é muito importante a congruência entre o conhecimento didáctico do conteúdo e o conhecimento pedagógico transmitido, e a forma como este se transmite. (MARCELO GARCÍA, 1999, p.29)

\section{PESQUISA: O CONTEXTO DE SUA PRODUÇÃO E ALGUMAS REFLEXÕES SOBRE A PRÓPRIA PRÁTICA}

Compreende-se que os desafios para a formação de professores não são novos. No entanto, é a partir dos anos finais do século XX que a atuação do formador de professores passa a ser mais questionada. Neste sentido, também as práticas dos docentes universitários vêm se constituindo um campo interessante de pesquisa nas últimas décadas, apontando para diferentes problemáticas, sobretudo aqueles referentes às lacunas de ordem didático-pedagógicas decorrentes do próprio processo de formação destes profissionais (ALMEIDA, 2012; CUNHA, 1998).

Indo além, acredita-se que é preciso refletir sobre a própria prática, numa perspectiva crítica, teorizada, embasando-se em dados levantados junto a grupos de alunos com os quais se trabalha aplicando, no desenvolvimento de suas próprias aulas, aquilo que se defende em teorias.

O saber experiencial é aquele construído pelo próprio sujeito durante sua prática: é um saber privado e pessoal; se for considerado como um talento, tal como o tesouro de faraó, será levado junto para o túmulo (DEWEY, 1929, citado por GAUTHIER et al., 1998). Ao longo do tempo que exerce sua função, o docente constrói uma espécie de jurisprudência composta por estratégias e formas de trabalho que the permite inferir que aquelas são as mais adequadas para resolver determinadas situações. $O$ que pode não ser verdadeiro. $E$ o fato de este saber ser privado e pessoal, ou seja, não ter passado pelo crivo de ser publicamente testado através de métodos científicos, faz com que ele seja limitado.

Os julgamentos feitos pelo docente e os motivos que lhes servem de apoio para as decisões que toma, uma vez explicitados, podem ser comparados e avaliados, buscando estabelecer regras de ação que podem ser conhecidas e aprendidas por outros sujeitos. Por esta razão, Gauthier et al. (1998) defendem que a profissionalização docente passa pela identificação dos saberes da ação pedagógica, ou seja, os saberes experienciais que, uma vez explicitados, sistematizados e validados pela academia, são passíveis de serem ensinados/aprendidos, podendo sustentar práticas docentes não apenas baseadas na experimentação (ensaio/erro), na tradição, no bom senso (que é um conceito relativo), e em habilidades que outros profissionais também podem ter.

Ampliando esta discussão, Tardif (2007) aponta que os docentes universitários devem realizar pesquisas e reflexões críticas sobre suas próprias práticas de ensino. Afirma o autor que, por vezes, existe um abismo entre as teorias professadas e as teorias praticadas, numa alusão de que muitos desses docentes não se veem como profissionais do ensino, apesar de elaborar teorias sobre o ensino, alertando que se 
[...] elaboramos teorias de ensino e aprendizagem que só são boas para os outros [...]. Então, se elas só são boas para os outros e não para nós mesmos, talvez isso seja a prova de que elas não valem nada do ponto de vista da ação profissional, a começar pela nossa (TARDIF, 2007, p. 276).

A busca por modificações das práticas pedagógicas dos docentes a partir de reflexões teorizadas, tanto daqueles que atuam na escola básica quanto nas universidades, decorre de diversos fatores. Entre estes, a demanda pela formação e atuação de professores dentro de uma perspectiva mais crítica e não fragmentada dos conteúdos. Os documentos legais que orientam a formação destes profissionais no Brasil (BRASIL, 2002, 2015) determinaram que os cursos de licenciatura promovessem modificações em suas estruturas curriculares, atendendo a cargas horárias e conteúdos mínimos. Indo além, também apontam para a superação do modelo formativo baseado na racionalidade técnica, ainda hegemônico na área de Ciências da Natureza e Matemática, pelo menos em termos de ideário, uma vez que muitos dos docentes formadores na área trazem consigo as marcas deste tipo de formação em suas práticas pedagógicas (CORTELA; NARDI, 2015b).

Também as crenças às quais os professores se apegam ao longo de sua formação parecem ser fortemente influenciadas tanto por determinados conhecimentos sistematizados quanto pela roupagem operacional que comandou o funcionamento da escola ao longo das gerações. (PENIN; MARTÍNEZ; ARANTES; 2009, p.36)

Entre outros aspectos, os modelos formativos atuais defendem que as disciplinas didático-pedagógicas sejam oferecidas desde o início do curso, com características integradoras, baseando-se em princípios das racionalidades prática com tendência à racionalidade crítica. De acordo com Carvalho e Vianna (1998, p.142) "[...] as disciplinas integradoras deverão proporcionar o caráter abrangente da formação do professor, englobando a adequação, organização e aplicação do conhecimento a ser lecionado [...]". As autoras supracitadas defendem que as disciplinas que abordam conteúdos específicos não podem ser simplesmente agregadas às de conteúdo didático-pedagógico: é preciso estabelecer uma interface entre elas visando à profissionalização do licenciando. Ou seja, faz-se necessário implementá-las e desenvolvê-las visando a transposição didática de conteúdos específicos, de tal modo que permitam o desenvolvimento de práticas que promovam a socialização das experiências pedagógicas capazes de favorecer a integração entre conceitos, disciplinas e áreas de conhecimento.

Neste sentido, as disciplinas que têm o caráter integrador objetivam formar e orientar os licenciandos em saberes e estratégias de ensino, de modo a adequar o ensino dos conteúdos específicos às faixas etárias dos alunos e níveis a que se destina, levando em consideração as diferentes especificidades, tanto de materiais didáticos quanto de alunos e das escolas onde estão inseridos.

Retomando o conceito de simetria invertida, faz-se necessário que o licenciando experiencie durante a própria aprendizagem aquilo que dele se espera enquanto profissional. Assim, para que este desenvolva práticas interdisciplinares, contextualizadas, relacionando teoria e prática, entre outras, como determinam as diretrizes de formação de professores, é preciso que tais práticas também estejam presentes em sua própria formação inicial. E é este desafio que os autores deste trabalho se propõem e cujos resultados, decorrentes de planejamentos e 
práticas sistemáticas e refletidas, por eles empreendidas, serão apresentados a seguir.

\section{A METODOLOGIA DA PESQUISA E DESCRIÇÃO DO CAMPO}

O estudo de caso é uma estratégia de pesquisa bastante comum também na atividade educacional. De acordo com Chizzotti (2006), visa, entre outros aspectos, reunir um conjunto de dados relevantes sobre o objeto de estudo com vistas a instruir ações posteriores. Também porque é considerado eficaz em estudos exploratórios, como é o caso da pesquisa maior do qual este excerto faz parte. Para tanto, faz-se necessário reunir informações de uma dada situação, a princípio particular, singular e delimitada, mas visando compreendê-la o mais amplamente possível, avaliando resultados de ações empreendidas.

Por exemplo, no estudo de uma organização, como a universidade, pode aprofundar conhecimentos a respeito de rotinas, currículos, entre outras; no que diz respeito a uma comunidade, o estudo pode se referir a um grupo relativamente homogêneo, com características profissionais específicas, como é o caso do curso de licenciatura em Física de uma universidade pública paulista.

Complementando, Bogdan e Biklen (1994, p.89) defendem que "O estudo de caso consiste na observação detalhada de um contexto, ou indivíduo, de uma única fonte de documentos ou de um acontecimento específico". No caso aqui apresentado, analisa-se um grupo de alunos de um curso de licenciatura em Física de uma universidade pública, refletindo sobre a constituição de uma identidade docente durante um conjunto de disciplinas didático-pedagógicas, de caráter integrador.

Stake (1994, citado por CHIZOTTI, 2006) também considera que o estudo de caso, no que diz respeito aos objetivos, pode ser intrínseco, instrumental ou coletivo. No caso aqui descrito, trata-se de um estudo de caso instrumental fundido com o estudo intrínseco, pois seus resultados estão servindo de apoio, ou pano de fundo, para dar continuidade a outras investigações, ou seja, orientar estudos subsequentes e também na tomada de decisões relativas à formação de novos professores.

Levando tudo o que foi acima explicitado, faz-se necessário explicitar o contexto de produção dos dados encontrados, apresentando e discutindo alguns aspectos relativos à estrutura curricular, às disciplinas onde ocorreram as coletas de dados; ao perfil profissional dos docentes formadores que nelas atuam; e ao perfil dos alunos participantes, que serão apresentados a seguir.

Neste estudo, o processo de análise do desenvolvimento de saberes docentes ocorre num curso de licenciatura em Física de uma universidade pública que, desde 2006, atende às Diretrizes Curriculares para formação de professores (BRASIL, 2002, 2015) adotando uma estrutura curricular que foge do modelo formativo conhecido por " $3+1$ " (três anos de disciplinas específicas e 1 ano das didático-pedagógicas), baseado na racionalidade técnica, hegemônico na área de Ciências da Natureza. Neste novo modelo formativo as disciplinas didáticopedagógicas são oferecidas desde o início do curso, dentro de uma perspectiva integradora, visando estabelecer interfaces entre os conteúdos específicos da Física e aqueles necessários ao seu ensino, currículo este estruturado com base na racionalidade prática, com tendência para a racionalidade crítica. 
Sua estrutura curricular está organizada em torno de três eixos: 1- Formação de conhecimentos básicos da Física e Ciências afins e seus instrumentais matemáticos; 2- A formação dos conhecimentos didático-pedagógicos do professor de Física - eixo integrador do curso; 3- Ciência, Tecnologia, Sociedade, Ambiente e Desenvolvimento Humano.

O modo como o curso foi estruturado (em 2006) e tem sido implementado, é considerado, pelos autores, como inovador na área. Isto porque, entre outros fatores, mesmo sendo uma determinação das Diretrizes Curriculares Nacionais (2002 e 2015), no que diz respeito à organização curricular e carga horária mínima, ainda é um modelo de difícil implantação. Ou seja, as mudanças relativas à forma como os docentes formadores ministram suas aulas, por exemplo, não dependem somente da legislação vigente ou das intenções dos proponentes das reformas.

[...] as políticas curriculares não se resumem aos documentos escritos, mas incluem também os processos de planejamento, vivenciados e construídos pelos diversos sujeitos envolvidos, em tempos e espaços múltiplos. Lopes (2004) afirma que os efeitos das políticas curriculares no contexto da prática são condicionados por questões institucionais e também disciplinares, num processo de interpretação das interpretações (CORTELA; NARDI 2015b, p.106).

Uma contribuição importante de pesquisas realizadas anteriormente, analisando este mesmo curso de licenciatura (CORTELA, 2004, 2011), foi o delineamento das características profissionais dos docentes formadores desta amostra em questão, suas histórias profissionais e como pensavam que deveria ser a formação de novos professores. O que ficou evidente é que a maioria dos participantes tinham (e ainda têm) o perfil do físico-pesquisador, decorrente de seu próprio processo formativo e de seu campo de atuação e que acabam por defender uma perspectiva mais conteudista e voltada à pesquisa para seus alunos, apesar de o curso ser uma licenciatura, no período analisado por Cortela (2004, 2011).

Em 2017, o departamento de Física da instituição analisada era composto por 22 docentes, a maioria ministrando disciplinas específicas (Eixo 1), um deles em disciplinas ligadas ao Eixo 3 e um deles em disciplinas do Eixo 2. No que diz respeito ao corpo docente atuante diretamente no curso de licenciatura em Física (37), além da maioria dos docentes anteriormente citados (22), cinco docentes estavam lotados no departamento de Matemática, ministrando disciplinas referentes ao instrumental matemático (Eixo 1); três docentes vinculados ao departamento de Química, ministrando disciplinas específicas (Eixo 1); três docentes lotados no departamento de Educação, ministrando disciplinas ligadas ao ensino de Física, e dois outros docentes ministrando disciplinas da área educacional geral (Eixo 2); e dois docentes do departamento de Ciências Humanas, ministrando aulas do Eixo 3. De forma global, um corpo docente altamente qualificado em seus campos de pesquisa, sendo 22 doutores, 10 pós-doutorados, 4 livres-docentes e 1 prof. Adjunto.

Quanto ao ano de graduação dos docentes formadores, levantados junto à Plataforma Lattes com vistas a compreender as condições de produção de suas práticas pedagógicas em relação aos modelos de ensino a que estiveram submetidos, verifica-se que a maioria deles (aproximadamente $89,47 \%$ ) foi formada entre 1972 e 2003, em cursos cujas estruturas curriculares adotavam, em 
sua maioria, modelos formativos conhecidos por " $3+1$ " ou mesmo " $2+2$ ", baseados na racionalidade técnica.

Pesquisas (CORTELA; NARDI, 2015a,b; NARDI; CORTELA; TAGLIATTI, 2018) apontam que, apesar de muitos dos atuais cursos de licenciatura em Física adotarem uma estrutura curricular que supera aos modelos formativos tipo " $3+1$ " ou " $2+2$ ", atendendo à legislação vigente para formação de professores e adotando uma distribuição disciplinar mais integrada, a maioria dos docentes formadores ainda não conseguiu superar abordagens de ensino e de avaliação pautadas na racionalidade técnica. Ou seja, a maioria continua a ministrar suas aulas adotando metodologias, instrumentos e critérios de avaliação considerados tradicionais.

No caso aqui apresentado, 28 dos docentes formadores trabalham com disciplinas do Eixo 1 representando, aproximadamente, 75,7\% dos formadores. São estes, também, os responsáveis pela maior carga horária do curso, sem levar em conta as disciplinas optativas.

Diferentes autores apontam que a inovação é um conceito polissêmico e que comporta diversas ideologias. CORTELA (2016), baseada em trabalhos de outros pesquisadores, considera os seguintes critérios para que algo seja considerado uma inovação educacional: 1- novidade; 2- originalidade; 3- raridade; 4racionalidade; 5- melhoria; 6- proponentes. Esses critérios levam em conta que nem sempre o que é considerado como novo para um sujeito o é em relação ao que já existe; trata-se de uma ideia original ou mesmo a forma como é posta em prática o é, representando um processo incomum; o tempo de vigência e/ou incorporação das novas práticas; o processo de planejamento de ações e/ou materiais com embasamento teórico; seus efeitos representam melhoria ou aperfeiçoamento do que já se tem; quem a propõe, quem a põe em prática e a quem atende.

Levando estes critérios em consideração, a forma como este projeto pedagógico de curso (PPC) foi constituído, o modo como a estrutura curricular e as disciplinas integradoras (Metodologias e Práticas de Ensino de Física I a V; Didática da Ciência; e Estágios supervisionados I a IV) foram organizadas e têm sido implementadas por docentes formados em Física, pós-graduados em Educação, com ênfase no ensino de Ciências, adotando resultados de pesquisas às idiossincrasias dos alunos e do curso em questão, produzindo também novos conhecimentos, esta experiência pode ser considerada também uma inovação na área de ensino de Física (NARDI; CORTELA, 2015).

Os conteúdos das disciplinas anteriormente citadas foram organizados de maneira a permitir uma formação que aproxime os resultados de pesquisa em ensino de Física da sala de aula e de modo a propiciar, tanto a integração dos conhecimentos adquiridos nas disciplinas teóricas e de laboratório, quanto à ampliação e aprofundamento de um corpo de conhecimentos voltados ao ensino.

É importante ressaltar que estas disciplinas, apesar de oferecidas por diferentes docentes, contam com um planejamento de ações, distribuição de temas e conteúdos elaborados em conjunto, visando à perspectiva integradora prevista no PPC do curso, tanto numa organização vertical, ou seja, considerando as disciplinas oferecidas em cada um dos semestres; como também numa perspectiva horizontal, pensando no desenvolvimento do curso como um todo, 
prevendo possíveis interfaces entre outras disciplinas ao longo da formação (ver Quadro 1, a seguir).

A intenção destes docentes formadores, ao organizarem as disciplinas abarcando diferentes temáticas e referenciais, adotando uma pluralidade metodológica e instrumentos e critérios de avaliação numa perspectiva formativa, é a de propiciar aos alunos, futuros professores, um arcabouço teóricometodológico que lhes permita avançar em seu processo formativo e profissional, com vistas à superação dos desafios de seu tempo, bem como possibilitar momentos em que possam exercer a regência em um ambiente simulado e com orientação de modo a suprir as lacunas, tanto em relação aos conteúdos específicos quanto aqueles relativos à transposição didática dos mesmos.

Quadro 1 - Temas e conteúdos desenvolvidos nas disciplinas de Metodologias e Práticas de Ensino de Física (I-V)

\begin{tabular}{|c|c|c|}
\hline Disciplina & $\begin{array}{l}\text { Fio condutor: } \\
\text { Conceitos chave }\end{array}$ & $\begin{array}{c}\text { Temas } \\
\text { abordados }\end{array}$ \\
\hline MPEF I & Mecânica & $\begin{array}{l}\text { 1- Breve História da Ed. Brasileira; } \\
\text { 2- Origens e evolução da pesquisa em ensino de } \\
\text { Física no Brasil; } \\
\text { 3- O ensino de Física: práticas, conteúdos e } \\
\text { pressupostos; } \\
\text { 4- Aspetos fundamentais da teoria de Piaget; } \\
\text { 5- O construtivismo e o mov. das concepções } \\
\text { alternativas; } \\
\text { 6- Modelos por Mudança Conceitual; } \\
\text { 7- Pesquisas sobre ensino de Mecânica; } \\
\text { 8- Critérios para análise de livros didáticos; } \\
\text { 9- Critérios de buscas em fontes de pesquisa; } \\
\text { 10- Planejamento didático; } \\
\text { 11- Elaboração e apresentação de sequências } \\
\text { didáticas (foco: Mecânica) }\end{array}$ \\
\hline MPEF II & Termodinâmica & $\begin{array}{l}\text { 1-Fundamentos legais para formação de prof. de } \\
\text { Física e o PPC do curso; } \\
\text { 2- Aspectos fundamentais da teoria de Vygotsky; } \\
\text { 3- O interacionismo e o ensino de Física; } \\
\text { 4- Modelo de Perfil conceitual; } \\
\text { 5- Documentos que orientam o ensino de Física; } \\
\text { 6- Pesquisas sobre o ensino em Termodinâmica; } \\
\text { 7- Análises dos Cadernos do Aluno do Est. de SP } \\
\text { (2a série do EM); } \\
\text { 8- Relações CTSA e o ensino de Física; } \\
\text { 9- Planejamento didático; } \\
\text { 10- Elaboração e apresentação de sequências } \\
\text { didáticas tendo como abordagem CTSA e/ou HC. } \\
\text { (foco:Termodinâmica) }\end{array}$ \\
\hline MPEF III & Eletromagnetismo & $\begin{array}{l}\text { 1- Saberes docentes e profissão docente; } \\
\text { 2- Estudos sobre Avaliações Externas (SAEB, } \\
\text { SARESP, ENEN) e seus impactos no trabalho } \\
\text { docente; }\end{array}$ \\
\hline
\end{tabular}




\begin{tabular}{|c|c|c|}
\hline & & $\begin{array}{l}\text { 3- Pesquisas sobre o ensino de Eletricidade e } \\
\text { Eletromagnetismo; } \\
\text { 4. Estratégias de ensino de Física para alunos } \\
\text { videntes e não videntes; } \\
\text { 5- Conhecimento Científico e conhecimento } \\
\text { Pedagógico: a transposição didática e o ensino de } \\
\text { eletromagnetismo; } \\
\text { 6- A experimentação como recurso de ensino; } \\
\text { 7- Elaboração e apresentação de sequências } \\
\text { didáticas tendo a experimentação como } \\
\text { abordagem (foco: Eletromagnetismo). }\end{array}$ \\
\hline MPEF IV & Óptica/Ondas & $\begin{array}{l}\text { 1-Fundamentos teóricos: aspectos da teoria de } \\
\text { Freire; } \\
\text { 2- O ensino de Física na EJA; } \\
\text { 4- A HFC e o Ensino de Física: resultados de } \\
\text { pesquisas; } \\
\text { 5- Pesquisas sobre o ensino em Ondas/Óptica; } \\
\text { 6. Preparação para o estágio: Teoria e prática de } \\
\text { observação de classes; } \\
\text { 7- Elaboração e apresentação de sequências } \\
\text { didáticas tendo como abordagem HFC no ensino } \\
\text { dos conceitos-chave. (foco: Ondas e Óptica) }\end{array}$ \\
\hline MPEF V & Física Moderna & $\begin{array}{l}\text { 1- Modelos de ensino nas diferentes abordagens; } \\
\text { 2- O ensino de Física em espaços não formais; } \\
\text { 3- A atualização curricular em relação à Física } \\
\text { Moderna; } \\
\text { 4- Análise de materiais didáticos que abordam } \\
\text { estes conteúdos no EM; } \\
\text { 5- O uso da TICs no ensino de Física; } \\
\text { 6- Orientações sobre escrita de artigo científico; } \\
\text { 7- Pesquisas sobre o ensino de FMC no EM; } \\
\text { 8- Elaboração de trabalho de conclusão de } \\
\text { disciplina, em forma de artigo, explorando o } \\
\text { ensino de FMC. }\end{array}$ \\
\hline
\end{tabular}

Fonte: Cortela, Gatti, Nardi (2016).

Por exemplo: no primeiro semestre, o aluno inicia o curso com Física I, disciplina na qual são trabalhados conteúdos que versam sobre a Mecânica, seus conceitos e teorias; em Laboratório de Física I, aqueles relativos à experimentação sobre Mecânica; e em Metodologia e Prática de Ensino I, resultados de pesquisas e fundamentos teórico-metodológicos que dão suporte ao ensino dos mesmos conceitos para a Educação Básica. Nessa disciplina, os estudos vão além da teoria, uma vez que os alunos elaboram e apresentam sequências didáticas sobre conteúdos relativos à Mecânica, recebendo orientações também em relação aos conteúdos específicos, uma vez que, como já dito, os professores que ministram estas aulas são formados em Física, com doutorado em Educação e pesquisam na área de ensino de Física. Adota-se a prática como componente curricular (PCC) em todas as disciplinas de metodologia de ensino, Didática da Ciência e optativas do curso.

Todas as MPEF ( a V), organizadas e ministradas por duas das autoras deste texto, desde 2013, envolvem estudos de referenciais teóricos, análise de livros e materiais didáticos em relação aos conteúdos-chave de cada semestre, elaboração e apresentação de sequências didáticas abordando os diferentes temas referentes 
ao ensino (Mecânica, Termodinâmica, Ondas, Eletromagnetismo e Física Moderna e Contemporânea), adotando diferentes abordagens e recursos. Além disso, também são desenvolvidas atividades referentes às práticas de leitura e de escrita de textos científicos, atendendo às solicitações presentes nas diretrizes curriculares de formação de professores, à época vigentes. (BRASIL, 2015).

As MPEF ( a V) têm duração de 60 horas cada uma, distribuídas em 15 encontros durante o semestre, um por semana. Quanto aos instrumentos e critérios de avaliação, estes são compostos por diversas atividades, visando às perspectivas somativa e formativa para avaliação da aprendizagem. Um cronograma de trabalho é apresentado logo no início do curso e, tanto os conteúdos quanto os instrumentos e critérios de avaliação, são discutidos conjuntamente com os discentes.

Oliveira, Pinho e Spazziani (2016, p. 110) fizeram um levantamento quanto ao perfil ingressante de alunos de todos os cursos universidade pública, foco deste artigo. Neste caso específico, "[...] o curso de licenciatura em Física e bacharelado em Física de Materiais atende majoritariamente a uma população de estudantes masculinos, jovens, de cor branca, oriundos de escolas públicas, residentes no interior de São Paulo, com renda familiar inferior a cinco salários mínimos e quase a metade deles exerce algum tipo de atividade remunerada.

O Quadro 2, a seguir, foi elaborado sistematizando dados referentes aos licenciados em Física, egressos do curso entre 2006 e 2017 tendo como critérios de organização: a estrutura curricular em cada um dos períodos citados (n.1602, n.1603, n.1604 e a n. 1605), a quantidade de vagas oferecidas, ano a ano, e a porcentagem aproximada de alunos formados em relação às vagas preenchidas.

Até 2012, o campus desta universidade pública ofertava somente o curso de licenciatura em Física, noturno; a partir de 2012, passou a oferecer também o curso de bacharelado em Física de Materiais, diurno, com entrada única. Por esta razão houve um aumento no número de ingressantes. Os alunos podem frequentar ambos os cursos de maneira concomitante, sendo que as disciplinas integradoras (Eixo 2) somente são obrigatórias para aqueles que pretendem o curso de licenciatura.

Vale salientar que o curso tem duração de quatro anos, mas o ingressante tem até oito anos para concluí-lo. É fato que durante o processo formativo muitos alunos passam por regime de dependência em algumas disciplinas, ou seja, nem todos que se formam em determinado ano pertencem, necessariamente, à mesma turma de ingresso. Também é possível que alunos em risco de jubilamento prestem novo vestibular e ingressem, novamente, no curso dentro de outra estrutura curricular. Mas a maioria dos alunos cumpre o curso em 4,5 anos. No entanto, na ausência de dados diferenciados a este respeito, foi calculada a média de formados desde o ano 2000 até o final de 2005, na estrutura n.1602 e que adotava o modelo formativo " $3+1$ ". A média calculada foi de $43,8 \%$ de concluintes (CORTELA; NARDI, 2015b).

Observa-se que o início do período apresentado no Quadro 2, 2006, apresenta um aumento no percentual de concluintes, sendo considerado, num primeiro momento, como 'um ponto fora da curva', ou seja, aquele que, em razão de uma característica especial, se distingue dos demais, dentro de uma mesma categoria, ultrapassando a média do período anterior que era, como já explicitado, de $43,8 \%$. No entanto, análises posteriores indicam que em 2007 e 2011 ocorrem dois picos 
ainda maiores na porcentagem de concluintes, sendo que no período de 2006 a 2011 a média de concluintes esteve em 57,5\%, com alunos cursando estruturas híbridas. Ou seja, a porcentagem de concluintes do curso aumentou consideravelmente entre 2006 e 2011 em relação ao período de 2000 a 2005.

Uma queda acentuada ocorreu entre 2012 e 2017 (média no período 16,67\%), no entanto, as estruturas curriculares eram muito semelhantes à n.1603. De forma mais específica, em 2014, 2015 e 2017 ocorre a menor quantidade de formandos desde o ano de 2000, sendo que somente a partir de 2015 formam-se os primeiros bacharéis (3).

Quadro 2 - Número de licenciados em Física egressos entre 2006-2017

\begin{tabular}{|c|c|c|c|c|}
\hline Ano & $\begin{array}{l}\text { Estrutura } \\
\text { Curricular }\end{array}$ & $\begin{array}{c}\text { Vagas } \\
\text { abertas }\end{array}$ & $\begin{array}{c}\text { Alunos } \\
\text { concluintes }\end{array}$ & Concluintes \\
\hline 2006 & $1602 / 1603$ & 40 & 21 & 52,50 \\
\hline 2007 & $1602 / 1603$ & 40 & 28 & 70,00 \\
\hline 2008 & $1602 / 1603$ & 40 & 19 & 47,50 \\
\hline 2009 & $1602 / 1603$ & 40 & 19 & 47,50 \\
\hline 2010 & $1602 / 1603$ & 40 & 23 & 57,50 \\
\hline 2011 & $1602 / 1603$ & 40 & 28 & 70,00 \\
\hline 2012 & $1603 / 1604$ & 60 & 22 & 36,70 \\
\hline 2013 & $1603 / 1604$ & 60 & 14 & 23,34 \\
\hline 2014 & $1603 / 1604$ & 60 & 7 & 11,67 \\
\hline 2015 & $1604 / 1605$ & 60 & 7 & 11,67 \\
\hline 2016 & $1604 / 1605$ & 60 & 11 & 18,34 \\
\hline 2017 & $1604 / 1605$ & 60 & 6 & 10,00 \\
\hline
\end{tabular}

Fonte: Autores (2018).

O curso de bacharelado em Física de Materiais teve início em 2012 e a provável formação da primeira turma estaria concluída ao final de 2015. Ou seja, no Quadro 2 todos aqueles que se formaram entre 2006 e 2014, são licenciados. Em 2015 formaram-se 10 alunos, sendo três bacharéis e sete licenciados; em 2016, 18 alunos, sendo sete bacharéis e 11 licenciados; em 2017, 11 alunos, sendo cinco bacharéis e seis licenciados.

Os dados apontam que ocorreu uma queda acentuada na porcentagem de concluintes no curso de licenciatura a partir de 2013. Não se pode afirmar sobre 
os motivos, mas vale registrar algumas constatações: i. que o grupo de docentes formadores permaneceu praticamente o mesmo desde 2010; ii. as estruturas curriculares n.1604 e n.1605 e seus respectivos Projetos Pedagógicos de Curso (PPC) pouco se alteraram em relação ao PPC e a estrutura curricular n.1603, reformulada com base em pesquisas realizadas, e que tiveram como foco o próprio curso (CORTELA, 2004, 2011; CAMARGO, 2007; KUSSUDA, 2012), e também em legislações vigentes (CNE/CP 01/2002 e 02/2015; CEE 126/2014). Ou seja, a queda não parece ter ocorrido em função desses elementos.

Algumas suposições para este declínio evidente no número de egressos, que ainda carecem de constatações e que serão confrontadas com novos dados a serem coletados ao final de 2019, seriam que: i. a forma como os docentes das disciplinas específicas passaram a atuar, oferecendo disciplinas de forma concomitante a ambos os cursos, que mantêm especificidades, acabaram por levar à uma maior evasão ou transferência de curso; ii. as condições de permanência oferecidas pela instituição, necessárias principalmente para este perfil de aluno, oriundo da classe média baixa e que necessita trabalhar para se manter, foram insuficientes; iii. as condições de trabalho e de valorização da profissão do professor da educação básica têm decaído e isso pode gerar desistência dos cursos de licenciatura, além da transferência para outros cursos, entre outras.

Nota-se, no entanto, que mesmo apresentando diminuição ao longo de alguns anos, o número de licenciados foi superior ao de bacharéis formados nos períodos considerados, tendo em vista o total de egressos: em 2015 formaram-se 10 alunos, sendo sete licenciados e três bacharéis (70\% e 30\%, respectivamente); em 2016, 18 alunos formados, sendo 11 licenciados e sete bacharéis $(61,2 \%$ e $38,8 \%$, respectivamente); em 2017, 11 alunos, sendo seis licenciados e cinco bacharéis (54,5\% e $45,5 \%$, respectivamente).

Assim, pode-se inferir que a licenciatura tem mantido/atraído maior número de alunos, uma vez que a entrada para os cursos é única e as escolhas se dão ao longo do processo formativo. E, como ambos os grupos de alunos cursam, praticamente, as mesmas disciplinas de conteúdos específicos da Física, é possível que o modo como as disciplinas didático-pedagógicas, que compõem o eixo integrador do curso, estão sendo planejadas e ministradas e o perfil profissional dos docentes formadores responsáveis por estas, têm garantido a permanência no curso e o interesse dos alunos pela profissão docente.

\section{RESULTADOS E DISCUSSÕES}

Os alunos participantes do levantamento aqui descrito são os mesmos, todos ingressantes na turma de 2015. Os dados foram coletados em dois momentos diferentes, numa perspectiva longitudinal. Visando analisar como estavam sendo constituídos os saberes necessários à docência durante o curso, foi aplicado um questionário semiestruturado com alunos iniciantes, durante a disciplina MPEF II, em 2015; e com alunos, mais experientes, em 2017, na disciplina MPEF V. Vale lembrar que se parte do pressuposto que a aquisição de saberes favorece a constituição de uma identidade profissional, no caso, uma identidade docente.

Neste sentido, fez-se importante apresentar como foram desenvolvidos os trabalhos nestas duas disciplinas, plano de fundo onde foram coletados os dados 
que serão apresentados. Ou seja, as condições de produção dos discursos encontrados.

No caso específico de MPEF II, oferecida no segundo semestre do curso, o conceito de Física, fio condutor das discussões (ver Quadro 1), é a Termodinâmica, dentro de outros temas específicos, que são: a. fundamentos legais para formação de professores de Física e suas atribuições; b. documentos oficiais que orientam o ensino de Física; c. aspectos fundamentais da teoria de Vygotsky; d. o interacionismo e o ensino de Física; e. O ensino com base no modelo de Perfil Conceitual; f. pesquisas sobre o ensino em Termodinâmica; g. análises de materiais didáticos; h. relações entre Ciências, Tecnologia, Sociedade e Ambiente (CTSA) e o ensino de Termodinâmica; i. elementos do planejamento didático; j. elaboração e apresentação de sequências didáticas tendo como foco CTSA no ensino de conceitos relativos à Termodinâmica para alunos de nível médio.

Os textos escolhidos buscam proporcionar aos licenciandos referenciais críticos para análise das políticas públicas educacionais e de materiais didáticos, com ênfase em conceitos da Termodinâmica, conteúdo-chave desta disciplina. Um dos principais objetivos é discutir o currículo para o ensino de Física, tanto em nível federal quanto estadual, bem como as abordagens de ensino sugeridas em documentos oficiais, tais como Atividade Centrada em Eventos (ACE), relações entre CTSA, e História e Filosofia da Ciência (HFC). Outro objetivo é discutir aspectos e conceitos centrais da teoria vigostkyana, que embasam os modelos de ensino dentro de uma perspectiva sociointeracionista, que é desenvolvida nesta disciplina. Vale lembrar que conceitos piagetianos são discutidos em MPEF I, saberes docentes e abordagens para alunos videntes e não videntes em MPEF III; abordagem freireana em MPEF IV. Para maiores detalhes, verificar Quadro 1.

Logo no início do curso os alunos recebem um cronograma de trabalho, contendo os textos e temas que serão discutidos ao longo do semestre, além do estabelecimento conjunto dos instrumentos e critérios de avaliação. $O$ trabalho de final da disciplina é uma sequência didática, abordando conteúdos da Termodinâmica previamente selecionados, destinados a alunos do 20 ano do Ensino Médio, analisando e discutindo a proposta de trabalho desenvolvida no material didático adotado pela Secretaria de Educação do Estado de São Paulo (SÃO PAULO, 2012), tendo como foco a experimentação e as relações CTSA.

Para tanto, os alunos são orientados desde o início da disciplina para realização de pesquisas em trabalhos publicados em eventos importantes da área, além de outros da literatura pertinente na área de ensino de Física e Educação. Ao final, as sequências são apresentadas aos demais colegas, podendo ser reformuladas a partir das críticas efetuadas, visando à melhoria do processo de planejamento, uma vez que se pretende uma avaliação formativa.

Quanto à MPEF V, os conceitos específicos, condutores das discussões, são aqueles desenvolvidos em Física Moderna e Contemporânea (FMC) (ver Quadro 1). Os temas tratados durante o semestre são: a. os modelos de ensino e as ideologias/teorias que os comportam; b. o ensino de Física em espaços não formais; c. atualização curricular em relação à FMC; d. análise de materiais didáticos que abordam estes conteúdos no Ensino Médio; e. uso das Tecnologias de Informação e Comunicação (TIC) no ensino de Física; f. orientações sobre a escrita de artigo científico; g. levantamento em revistas científicas sobre o ensino de FMC no EM; i. elaboração de trabalho científico, em formato similar aos 
apresentados em eventos da área. Os instrumentos de avaliação da disciplina são: elaboração de resumos informativos de parte dos textos estudados; sínteses de levantamentos realizados em eventos, abordando temas relativos ao ensino de FMC; elaboração de sequência didática desenvolvendo conteúdos referentes ao 3 o ano do ensino Médio; esboço de um trabalho científico.

Esta disciplina é oferecida no 5o semestre do curso e, juntamente com a disciplina de Estágio Supervisionado I, acompanha o início das atividades de docência em escolas da educação básica. Assim, o primeiro tema a ser discutido são os modelos de ensino, retomando pontos já trabalhados em disciplinas anteriores e aprofundando reflexões e estudos que propiciarão práticas teorizadas, explorando novas perspectivas metodológicas a partir de discussões a respeito da função social da escola.

No que diz respeito à forma e tempos em que os dados foram coletados, o instrumento utilizado em 2015 foi um questionário semiestruturado, composto por dez questões que abordaram diferentes enfoques. Foram apresentadas, aqui, sínteses das respostas encontradas em duas delas, por trazerem à tona pontos de uma mesma problemática: opiniões a respeito dos saberes que os bons professores dominam e o grau de satisfação com a profissão escolhida. Quanto ao instrumento aplicado em 2017, também semiestruturado, este continha oito questões, sendo analisadas neste artigo apenas duas delas, pelo mesmo motivo apresentado anteriormente.

Quanto aos participantes da pesquisa, a turma de MPEF II era composta por 39 alunos, sendo que 29 deles responderam ao questionário. Quanto aos alunos que cursaram MPEF V em 2017 (15), 11 responderam ao questionário, sendo que dez deles foram também participantes da pesquisa em 2015. Optou-se por analisar apenas aqueles que responderam a ambos os questionários, ou seja, 10 licenciandos.

Os dados apontam que 50\% desta amostra alunos da turma de MPEF II, em 2015, tinham a pretensão de ministrar aulas após concluir o curso, seja em nível médio ou superior. Ou seja, apenas a metade deles pretendia exercer a profissão no início de um curso de licenciatura que, no caso aqui discutido, pode ser cursado de forma concomitante com o bacharelado. Quanto aos alunos da turma de MPEF V, em 2017, 100\% deles afirmaram pretender atuar como professores, mas não necessariamente no ensino médio, para o qual são formados, mas também no ensino superior.

Os dados apontam que entre os ingressantes (turma MPEF II), 54\% gostariam de lecionar, $30 \%$ pretendiam fazer pós-graduação; $5 \%$ fazer outros cursos, ou seja, os dados apontam que $35 \%$ pretendiam dar continuidade aos estudos. Entre os mais experientes (turma MPEF V), 34\% pretendiam lecionar; 33\% fazer uma pósgraduação e $12 \%$ fazer outros cursos: ou seja, $46 \%$ dos respondentes pretendiam a continuidade dos estudos. Estes valores podem indicar tanto o entendimento do aperfeiçoamento profissional como um processo contínuo; quanto que o curso de pós-graduação Ihes possibilitaria o acesso à docência no ensino superior, que têm um prestígio maior e um campo de trabalho diferenciado, possibilitando também a pesquisa.

Quando perguntados sobre o grau de satisfação com a profissão, numa Escala Likert ( 1 representa insatisfeito e 5 plenamente satisfeito), as respostas dos alunos da turma de 2017 apontam para um nível de satisfação de intermediário para alto: 
1 (0\%); 2 (0\%); 3 (70\%); 4 (20\%); 5 (10\%). Ou seja, 100\% dos sujeitos atribuíram valores iguais ou acima de 3 , valores estes que apontam uma identificando com a profissão. Quando perguntados sobre as justificativas para não atuarem na educação básica, os argumentos apresentados não têm nenhuma relação com o curso em si, mas sim com as condições desfavoráveis de trabalho dos professores no Brasil, principalmente daqueles que atuam na rede pública e básica de ensino; a falta de valorização da profissão; o temor quanto às dificuldades com a indisciplina e/ou apatia dos alunos, baixos salários, entre outras. Quanto àqueles que apontaram valores mais altos de satisfação $(10 \%)$, nenhum deles estava realizando estágio supervisionado, ministrando aulas, ou participando de projetos de iniciação à docência. Ou seja, a opinião não parece ser decorrente de experiência enquanto professor. Como justificativas, esses respondentes apontam a esperança por dias melhores ou questões ligadas ao altruísmo.

Fica evidente nas respostas comparadas em dois momentos que houve um aumento no interesse pela profissão e isso pode ser decorrente de diversos fatores, não considerando as escolhas pessoais que não foram alvo do levantamento. Entre estes: o modelo formativo adotado desde 2006, que favoreceu uma estrutura curricular mais orgânica; a presença das disciplinas integradoras desde o início do curso; o modo conjunto como as disciplinas que fundamentam a formação dos conhecimentos didático-pedagógicos do professor de Física são planejadas e desenvolvidas pelos docentes responsáveis por elas; e o perfil profissional dos docentes formadores que as ministram, entre outras. Acredita-se que todos estes fatores tenham impactado positivamente na aquisição de saberes e também na constituição de uma identidade profissional docente, mesmo que essa se dê em nível superior.

Quanto às respostas referentes às características dos bons professores, estas foram organizadas em dois grandes grupos: as pessoais e as profissionais. Entre aquelas classificadas como pessoais, ligadas basicamente à personalidade, as mais citadas foram: boa comunicação; paciência; atenção; altruísmo; ser justo; ser espontâneo; bom ouvinte; ser flexível e dinâmico. Entre aquelas classificadas como profissionais estão: domínio da matéria a ser ensinada; boa interação com os alunos; capacidade de "transmitir" conhecimentos (termo utilizado pelos respondentes); boa didática (numa perspectiva de senso comum, como um "jeito de dar aula"); alguém que respeite as diferenças, que cumpra com horários, prazos e metas, ou seja, características ligadas ao planejamento e execução do trabalho docente.

Entre os alunos iniciantes, de modo geral, $51 \%$ das respostas indicaram caraterísticas pessoais e $49 \%$ profissionais. Entre os mais experientes, $44 \%$ apontaram caraterísticas pessoais e $56 \%$ apontam para as profissionais. Estes valores apontam que ao longo do processo formativo os licenciandos vão compreendendo e valorizando mais os aspectos profissionais, que são aqueles passíveis de serem ensinados/aprendidos, superando uma percepção vocacional ou mesmo sacerdotal da profissão docente, advinda do senso comum.

Também foi solicitado aos alunos que citassem cinco saberes que os bons professores dominam. As respostas foram agrupadas nas categorias de saberes propostas por Tardif (2007): pessoais; disciplinares (domínio dos conteúdos específicos e das teorias da Educação); aqueles decorrentes da formação profissional (metodologias, avaliação, planejamento); e os curriculares. 
Quadro 3 - Sínteses das respostas dadas pelos alunos em 2015 e em 2017

\begin{tabular}{|c|c|c|c|c|c|}
\hline \multicolumn{7}{c}{ Saberes que os bons professores dominam } \\
$\begin{array}{c}\text { Disciplina } \\
\text { (ano) }\end{array}$ & Pessoais & Disciplinares & $\begin{array}{c}\text { Da formação } \\
\text { profissional }\end{array}$ & Curriculares & Experienciais \\
\hline $\begin{array}{c}\text { MPE II } \\
(2015)\end{array}$ & $70 \%$ & $60 \%$ & $60 \%$ & $20 \%$ & $0 \%$ \\
\hline $\begin{array}{c}\text { MPE V } \\
(2017)\end{array}$ & $30 \%$ & $90 \%$ & $100 \%$ & $70 \%$ & $90 \%$ \\
\hline
\end{tabular}

Fonte: Autores (2018).

Observa-se uma diferença bastante acentuada nos valores encontrados, principalmente em relação ao decréscimo em relação aos saberes de cunho pessoal (de $70 \%$ para $30 \%$ ); o aumento substancial em relação àqueles relativos à profissionalização do sujeito, ou seja, aqueles relacionados ao que foi chamado de disciplinares (de 60\% para 90\%); da formação profissional (de 60\% para 100\%), curriculares (de $20 \%$ para $70 \%$ ); e experienciais (de $0 \%$ para $90 \%$ ).

Como afirmam Gauthier et al. (1998) a respeito dos saberes curriculares, os programas não são produzidos pelos professores, mas devem ser por eles conhecidos, uma vez que lhes servem de guia para o planejamento e avaliação de suas ações. E, no caso aqui descrito, os alunos apontam a importância deles na composição dos saberes que os bons professores dominam.

Interessante analisar os dados relativos aos saberes experienciais. Tendo em vista que os alunos em 2017, como já explicitado, não estavam ainda realizando estágio supervisionado, ministrando aulas, ou participando de projetos de iniciação à docência, como se justifica este aumento da importância destes saberes? Acredita-se que a adoção da prática como componente curricular (PCC), nos termos da legislação vigente para formação de professores, empreendida em todas as disciplinas do eixo 2 , integrador do currículo, tenha sido responsável por este diferencial.

Como já foi apontado na legislação, esse contato com a prática real de sala de aula não deve ficar restrita apenas aos estágios supervisionados.

\footnotetext{
[...] a prática contextualizada pode "vir" até à escola de formação por meio das tecnologias de informação - computador e vídeo -, de narrativas orais e escritas de professores, de produções dos alunos, de situações simuladas e estudos de casos. Os recortes da tematização podem ser definidos segundo os objetivos de cada situação de formação pode-se optar por tematizar aspectos específicos da prática ou a prática contextualizada em sua totalidade. (BRASIL, 1999, p. 109).
}

Assim, a adoção da prática como componente curricular em atividades como: critérios para escolha de livros didáticos, sugeridas pelo PNLD, como uma simulação de uma das atividades de responsabilidade do professor da escola básica (em MPEF I); o uso de filme como recurso didático, tendo como foco as relações CTSA, a importância de uma abordagem histórica da Ciência e as questões de gênero (em MPEF II); o estudo e o desenvolvimento de propostas de recursos didáticos para alunos videntes e não videntes (em MPEF III); o planejamento de atividades para a Educação de Jovens e Adultos e a aplicação desta atividades em situações reais em escolas que atendem a este público-alvo (em MPEF IV e em um 
projeto de extensão denominado "O outro lado da Física", desenvolvido na disciplina de Estágio supervisionado); o levantamento de softwares e simuladores para o ensino de conteúdos de FMC no ensino médio (em MPEF V); e atividades de análise (Exame Nacional do Ensino Médio-ENEM, Sistema de Avaliação de Rendimento Escolar do Estado de São Paulo-SARESP) e elaboração de questões para avaliação da aprendizagem (em Didática da Ciência), entre outras, parecem ter favorecido à constituição de uma identidade docente nos licenciados analisados.

\section{CONCLUSÕES}

Neste artigo procurou-se refletir sobre os fatores que influenciam o processo de construção de uma identidade docente durante a formação inicial de professores de Física. Em relação a esta amostra de alunos, os dados coletados entre 2015 e 2017 apontam que houve uma apropriação de conhecimentos e saberes ao longo de três anos iniciais do curso e que lhes permitiu a construção de uma identidade docente, em processo de aprimoramento. Ou seja, de $50 \%$ passouse a $100 \%$ daqueles que pretendiam trabalhar como docentes após a conclusão do curso.

Entre os fatores que contribuíram com estes resultados acredita-se estar: a adoção oficial de um modelo formativo baseado na racionalidade prática; a reformulação da estrutura curricular do curso numa perspectiva mais orgânica; a distribuição das disciplinas integradoras na estrutura curricular, desde o início do curso e pensadas conjuntamente com as de Estágio Supervisionado, que ocorre nos dois últimos anos do curso (5 a 8 o semestres); a adoção da PCC em todas as disciplinas do Eixo 2, integrador do curso; no modo as disciplinas que fundamentam a formação dos conhecimentos didático-pedagógicos do professor de Física são planejadas e desenvolvidas em conjunto entre os docentes responsáveis por elas; e também o perfil profissional dos docentes que as ministram, todos formados em Física, com pós-graduação em Educação com ênfase no ensino de Ciências e Matemática e que pesquisam na área de ensino de Física e formação de professores.

O perfil profissional desses docentes formadores lhes permite contribuir também com parte dos conhecimentos específicos, preenchendo lacunas conceituais, ainda presentes e perceptíveis nas práticas pedagógicas propostas pelos alunos. O planejamento docente conjunto, discutindo temas, referenciais da área de ensino de Física, metodologias, instrumentos e critérios de avaliação adotados permite aos educandos perceberem que existe um planejamento coletivo, dentro de um fio condutor, um cuidado com a perspectiva interdisciplinar e integradora pretendida no PPC.

Os resultados de um processo de planejamento coletivo das ações, desde 2013, realizado pelos docentes que ministram as disciplinas integradoras, estão favorecendo não só práticas pedagógicas melhor fundamentadas e interligadas, como também a construção de uma identidade docente a partir da incorporação de novos saberes, que não estavam presentes, ou eram insuficientes, nos discursos de alunos ingressantes, e que apontam para o potencial formativo das abordagens adotadas. 
O fato de os docentes pesquisarem sobre temas relacionados ao ensino de Física, políticas públicas sobre formação de professores, entre outros, permite que as disciplinas possam ser continuamente redimensionadas e reorganizadas a partir de novas teorias, realimentando o processo de pesquisa e colaborando no sentido de propiciar uma formação que atenda, basicamente, às demandas e desafios atuais do ensino na Educação Básica. Mas, que ainda assim, esbarram em fatores como a desvalorização do trabalho docente, baixos salários e condições de trabalho desfavoráveis e que acabam por desmotivar os licenciados a trabalharem na educação básica pública.

Outro ponto que corrobora esta análise é que à medida que avançam na graduação, a vontade de continuar os estudos, seja em cursos de pós-graduação, seja fazendo outras graduações, aumenta de $35 \%$ para $46 \%$. Estes valores podem indicar tanto o entendimento do aperfeiçoamento profissional como um processo contínuo, quanto o fato que o curso de pós-graduação possibilitar aos egressos dos cursos de graduação o acesso à docência no ensino superior, que têm maior prestígio e um campo de trabalho diferenciado, possibilitando também a pesquisa.

A estrutura curricular, mudada em 2006 por força de lei foi, aos poucos mostrando seu potencial formativo, tanto que dados levantados por pesquisas (NARDI; CORTELA, 2015) apontam que os índices de profissionais formados neste programa subiram durante os anos de 2007 a 2011 de maneira bastante significativa (de $52,5 \%$ para $70,0 \%$ ). E mesmo com a queda acentuada no número de egressos a partir de 2012, o número de licenciados ainda é superior ao de bacharéis formados nos períodos considerados, tendo em vista o total de ingressantes. Assim, pode-se inferir que a licenciatura tem atraído/mantido maior número de alunos. Ou seja, o aumento das cargas horárias dos estágios supervisionados, a distribuição das disciplinas didático-pedagógicas ao longo de todo o curso e a adoção da PCC, permitiram o desenvolvimento de práticas integradas, menos fragmentadas e prevendo possíveis interfaces, favorecendo a permanência do aluno no curso. Além de programas incentivadores à docência e que permitem acesso a bolsas, como o Programa Institucional de Bolsa de Iniciação à Docência (PIBID) e Residência Pedagógica.

Defende-se que todos estes fatores tenham impactado positivamente na aquisição de saberes e também na constituição de uma identidade profissional docente, mesmo que essa se dê em nível superior.

No entanto, um fato preocupante foi a queda no número de formandos de ambos os cursos, que ocorreu após a abertura curso de bacharelado, em 2012. Ou seja, a primeira turma de bacharéis deveria ter concluído seus estudos a partir de 2015. Os dados apontam que se formaram, desde então, apenas 15 bacharéis, cinco em média a cada ano, em média aproximadamente $8,4 \%$ em relação aos alunos ingressantes no mesmo período. Trata-se de um dado relevante a ser discutido pelo grupo de docentes formadores e coordenação de curso, visando equacionar esta questão. 


\title{
IDENTITY AND TEACHER'S KNOWLEDGE CONSTITUTIONS DURING THE INITIAL TRAINING OF PHYSICS TEACHERS: A CASE STUDY
}

\begin{abstract}
It is an excerpt from an investigation that seeks to study the process of constitution of the teaching identity in different formative times from the acquisition of knowledge. It aims to analyze the multiple relationships that involve the acquisition and mobilization of the same in different stages, from the initial formation until the exercise of the profession. We report here a case study carried out with students of a degree in Physics, in the disciplines of Teaching Methodologies and Practices, in a longitudinal perspective. The instrument for data collection was a semi-structured questionnaire. Summaries of the answers concerning the knowledge of good teachers and satisfaction with the profession chosen are presented. It is concluded that throughout the course the students broaden and deepen their knowledge, favored, among other aspects: by the way the curricular structure of the course was organized; by the way the teachers of the didactic-pedagogical disciplines work; and by the profile of these trainers.
\end{abstract}

KEYWORDS: Teacher's identity. Teacher's knowledge. Professionality. 


\section{REFERÊNCIAS}

ALMEIDA, M. I. Formação do professor do ensino superior: desafios e políticas institucionais. São Paulo: Cortez, 2012.

BORGES, C.M.F. O professor da Educação Básica e seus saberes profissionais. 1a edição, Araraquara-SP, JM Editora, 2004.

BRASIL. Referenciais para formação de professores. Brasília: Ministério da Educação/Secretaria de Educação Fundamental (MEC/SEF), 1999.

BRASIL Resolução CNE/CP 1/2002, de 18 de fevereiro de 2002. Diretrizes Curriculares Nacionais para a formação de professores de Educação Básica, em nível superior, curso de licenciatura, de graduação plena. Diário Oficial da União. Brasília, 2002.

BRASIL (2015). Resolução CNE 02/2015, de 01 de julho de 2015. Diretrizes curriculares nacionais para formação inicial em nível superior (cursos de licenciatura, cursos de formação pedagógica para graduados e cursos de segunda licenciatura) e para a formação continuada. Diário Oficial da União. Brasília. 02/07/2015. Sessão 1, p. 8-12.

BRZEZINSKI, I. (Org.). Profissão professor: identidade e profissionalização docente. Brasília: Plano Editora, (2002).

CAMARGO, S. Discursos presentes em um processo de reestruturação curricular de um Curso de Licenciatura em Física: o legal, o real e o possível. 2007. $285 f$. Tese (Doutorado em Educação para a Ciência), 2007.

CARVALHO, A. M. P.; Vianna, D. M. A quem cabe a licenciatura? Ciência e Cultura, São Paulo, 1998, n.40 v. 2, 143-163.

CHIZZOTTI, A. Pesquisa qualitativa em ciências humanas e sociais. Petrópolis, RJ: Vozes, 2006.

CORTELA, B. S. C. Práticas inovadoras no ensino de graduação na perspectiva de professores universitários. Revista Docência do Ensino Superior, v.6, n.2 out.2016, p.9-34. 
Formadores de Professores de Física: uma análise de seus discursos e como podem influenciar na implantação de novos currículos. Dissertação (Mestrado em Educação para a Ciência), 2004.

CORTELA, B. S. C; GATTI, S. R.T; NARDI, R. A construção de uma identidade docente desde a formação inicial de professores de física. In: MARQUES, A. F.; GIARDINETTO, J. R. B; MACHADO, V. Caderno de Docência na educação básica V: o ensino na educação básica- desafios didáticos. São Paulo, Cultura Acadêmica, 2016, p. 45-58.

CORTELA, B. S. C; NARDI, R. Expectativas de docentes formadores frente a um processo de reestruturação curricular em um curso de licenciatura em Física. In: NARDI, R.; CORTELA, B.S.C. (Orgs.) Formação Inicial de professores de Física em Universidades Públicas: estudos realizados a partir de recentes reestruturações curriculares. São Paulo: Editora Livraria da Física, 2015a, p.47-74

CORTELA, B. S. C; NARDI, R. A constituição de um perfil identitário de um curso de Física. In: NARDI, R.; CORTELA, B.S.C. (Orgs.) Formação Inicial de professores de Física em Universidades Públicas: estudos realizados a partir de recentes reestruturações curriculares. São Paulo: Editora Livraria da Física, 2015b, p 99132.

CUNHA, M.I. O professor universitário na transição de paradigmas. Araraquara, SP.: Junqueira \& Martins, 1998.

DUBAR, C. A socialização: construção das identidades sociais e profissionais. São Paulo: Martins Fontes, 2005.

GAUTHIER, C. et al. Por uma teoria da pedagogia: pesquisas contemporâneas sobre o saber docente. Ijuí: Editora UNIJUÍ, 1998.

KUSSUDA, S.R. A escolha profissional de licenciados em Física de uma universidade pública. 2012, 184f. Dissertação (Mestrado em Educação para Ciência). Faculdade de Ciências, Universidade Estadual Paulista, Bauru, 2012.

LIBÂNEO, J. C. Produção de saberes na escola: suspeitas e apostas. In: CANDAU, V. M. (Org.). Didática, currículo e saberes escolares. Rio de Janeiro: DP \& A, 1145, 2000.

MARCELO, C.G. Formação de professores_Para uma mudança educativa. Porto, Portugal: Porto Editora, 1999. 
NARDI, R.; CORTELA, B.S.C. Formação Inicial de professores de Física: novas diretrizes, antigas contradições. In: NARDI, R.; CORTELA, B.S.C. (Orgs.) Formação Inicial de professores de Física em Universidades Públicas: estudos realizados a partir de recentes reestruturações curriculares. São Paulo: Editora Livraria da Física, 2015.

NARDI, R; CORTELA, B.S.C; TAGLIATTI, J. R. Um estudo sobre os potenciais formativos de cursos de licenciatura em Física do Estado de Minas Gerais. Revista Brasileira de Ensino de Ciência e Tecnologia, v. 11, p. 384-402, 2018.

OLIVEIRA, J. B. B; PINHO, S. Z.; SPAZZIANI, M. L. (Orgs.) Perfil socioeconômico e cultural dos ingressantes dos cursos de graduação: 2006-2015: ciências exatas e da terra. São Paulo: Universidade Estadual Paulista, Pró-Reitoria de Graduação, Vunesp, 2016.

PENIN S, MARTíNEZ, M., ARANTES, V. A. (Org.). Profissão docente: pontos e contrapontos. São Paulo: Summus, 2009.

PIMENTA, S. G. Formação de Professores: identidade e saberes da docência. In. PIMENTA, S. G. (Org.). Saberes Pedagógicos e Atividade Docente. São Paulo: Cortez, 2002, 15-38.

SÃO PAULO (Estado). Secretaria da Educação. Currículo do Estado de São Paulo: Ciências da Natureza e suas tecnologias. FINI, M.I; MENEZES, L.C. SÃO Paulo: SE, 2012.

SCHÖN, D. A. Educando o profissional reflexivo: um novo design para o ensino e a aprendizagem. Porto Alegre: Artes Médicas, 2000.

TARDIF, M. Saberes Docentes e Formação Profissional. Petrópolis, RJ: Vozes, 2007.

TARDIF, M., LESSARD, C. Trabalho docente. Petrópolis: Vozes, 2005.

VEIGA, I. P. A. Projeto político-pedagógico da escola: uma construção possível. Campinas: Papirus, 2009.

ZEICHNER, K. M.; Pereira, J. E. D. Pesquisa dos educadores e formação docente voltada para a transformação social. Caderno de Pesquisa, 35 (125), 63-80, maio/agosto, 2005. 
Recebido: 18 jun. 2018.

Aprovado: 10 mar. 2019.

DOI: $10.3895 /$ rbect.v13n2.8444

Como citar: CORTELA, B. S. C.; GATTI, S. R. T.; NARDI, R. Identidade e saberes docentes constituídos

durante a formação inicial de professores de física: um estudo de caso. Revista Brasileira de Ensino de Ciência e Tecnologia, Ponta Grossa, v.13, n. 2, p. 18-42, mai./ago. 2020. Disponível em:

$<$ https://periodicos. utfpr.edu.br/rbect/article/view/8444>. Acesso em: XXX.

Correspondência: Beatriz Salemme Corrêa Cortela - biacortela@fc.unesp.br

Direito autoral: Este artigo está licenciado sob os termos da Licença Creative Commons-Atribuição 4.0 Internacional.

(c) (1) 